\title{
Representaciones de aves en la iconografía de la cultura Jama-Coaque
}

Pablo A. Quelal M. ${ }^{1}$

\section{RESUMEN}

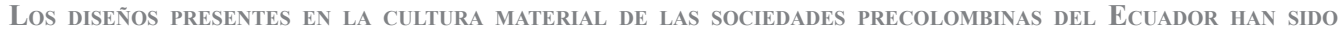
INVESTIGADOS GENERALMENTE DESDE UNA PERSPECTIVA FORMAL. EN ESTE ESTUdIO PROPONEMOS UN INTENTO DE ANÁlisis CONTEXTUAL RELACIONAL DE LAS REPRESENTACIONES DE AVES EN JAMA-COAQUE COMO UNA PRIMERA APROXIMACIÓN INTERPRETATIVA, QUE PUEDA CONTRIBUIR AL ENTENDIMIENTO DE UNA COSMOVISIÓN MÁS AMPLIA DE ESTA SOCIEDAD PRECOLOMBINA EN RELACIÓN CON ESTE TIPO DE FAUNA.

Palabras clave: Jama-Coaque - Aves - Iconografía - Metáfora - Semiótica

\section{Abstract}

THE DESIGN ELEMENTS PRESENT IN PRE-COLUMBIAN SOCIETIES OF ECUADOR HAVE BEEN INVESTIGATED GENERALLY FROM A FORMAL PERSPECTIVE. IN THIS STUDY WE PROPOSE A RELATIONAL CONTEXTUAL ANALYSIS OF THE REPRESENTATION OF BIRDS IN JAMA-COAQUE AS A FIRST INTERPRETATIVE APPROXIMATION, WHICH CAN CONTRIBUTE TO THE UNDERSTANDING OF A WIDER WORLDVIEW OF THIS PRE-COLUMBIAN SOCIETY IN RELATION TO THIS KIND OF WILDLIFE.

Key WORdS: JAMA-COAQUe - BIRDS - ICONOGRAPHY - METAPHOR - SEMIOTICS.

1 El presente artículo corresponde a la síntesis elaborada a partir de mi tesis de disertación para la obtención del título de Antropólogo con mención en Arqueología que lleva el mismo título, PUCE, Quito, Ecuador, octubre 2013. Antropólogo PUCE/ pqjanro18@gmail.com 


\section{Introducción}

1 desarrollo de la ciencia arqueológica ha llevado a sus especialistas hacia el abordaje de disciplinas diferentes en pos de una comprensión más amplia de las sociedades pretéritas a partir de sus restos materiales. De esta manera nos hemos interesado en las imágenes de aves en un conjunto de figurinas correspondientes a la cultura precolombina Jama-Coaque. Estas imágenes plasmadas en la cultura material permiten llevar a cabo una aproximación a su pensamiento, tomando como primer acercamiento su relación con las aves.

Mediante la interrelación de los diseños plasmados en el conjunto material, tanto de aves como otros diseños zoomorfos y antropomorfos; y el tipo de artefacto contenedor del diseño, los diseños de la cultura Jama Coaque muestran una tendencia a representar a las aves en un estilo naturalista que, mediante su combinación con atavíos, como collares y brazaletes, permitiría la conceptualización de esta especie animal en la mente de los individuos, lo cual puede también traducirse en una acción de apoderamiento de la naturaleza por parte del ser humano.

Estas interrelaciones en el material cultural, nos permiten realizar la vinculación entre arqueología e iconografía para un análisis relacional de imágenes. Este tipo de estudios no han sido muy frecuentes en la arqueología ecuatoriana y de los pocos existentes, son escasos los estudios a profundidad sobre la iconografía precolombina del país.

"El arte es una parte integrante de cualquier sociedad y nuestro conocimiento del arte del antiguo Ecuador podrá apreciarse realmente, mediante el descubrimiento científico de piezas dentro del contexto en que los colocó la sociedad que los elaboró" (T. Cummins 1992, en Valdez y Veintimilla, 1992: 81).

\section{Investigaciones previas}

Los primeros en preocuparse, si cabe el término, sobre la evidencia Jama-Coaque fueron Marshall Saville (1907) y Víctor Emilio Estrada (1957) quienes, cada uno en su tiempo, realizaron excavaciones y descripciones del material de esta cultura precolombina, siempre destacando la fastuosidad de las decoraciones de los personajes antropomorfos tanto para su cabeza como en su cuerpo. Sin embargo, solo en la década de 1980, bajo el Proyecto Arqueológico/ Paleoetnobotánico del Valle de Jama, liderado por James Zeidler y Deborah Pearsall, fue posible tener análisis más complejos, como por ejemplo una secuencia estratigráfica refinada, obtenida del sitio San Isidro, en la que se presenta una ocupación cultural desde Valdivia en el período Formativo Temprano, pasando por ocupaciones Chorrera hasta Jama-Coaque en el período Integración. Esto quiere decir que abarca un lapso temporal de 3000 años, aproximadamente (Zeidler et al., 1994).

La tola presente en San Isidro sugiere a los autores que se trataba de un centro ceremonial y administrativo durante la ocupación larga de Jama-Coaque en el sitio, construido entre las fases Muchique 1 y Muchique $3^{2}$ (355 10 a.C. -1258 d.C.)(Ibid.: 73). Para afinar esta cronología, el proyecto visitó los sitios de La Mina, El Tape y Don Juan. Una serie de sondeos en los niveles superiores de estos dos sitios revelaron depósitos arqueológicos afiliados a la ocupación JamaCoaque del período de Integración, secuencia que en La Mina se extiende hasta el período colonial (Ibíd.: 102), sin cambios estilísticos provocados por erupciones volcánicas ${ }^{3}$.

2 La larga tradición Jama-Coaque está representada por cuatro fases cerámicas principales en el valle de Jama, designadas Muchique 1, 2, 3, y 4, de las cuales sólo las tres primeras han sido documentadas en San Isidro (Zeidler et al, 1994: 86)

3 La hipótesis propuesta en estos eventos es que la población se movilizó hacia las laderas, adaptación que permitió la continuidad cultural que se manifiesta en la evidencia material dado que los suelos altos permitieron un rápido reinicio de las actividades agrícolas post erupción (Zeidler et al, 1994: 138). 
Finalmente, con los estudios previos, Thomas Cummins muestra interés en la cultura JamaCoaque con respecto a sus sellos cerámicos. Su trabajo se caracteriza por hacer un inventario de los diseños presentes en estos artefactos, a partir de los cuales realiza consideraciones que se limitan a un carácter formal, mencionando ciertas similitudes con diseños mesoamericanos. La mayor contribución que hace este catálogo es notar que los diseños de los sellos no son los mismos que aquellos presentes en vasijas y figurinas (Cummins, 1996: 22-25). Alden Yépez (2010: 5) anota que esta diferenciación hace pensar que los sellos y las figurinas gozan de su respectiva "gramática propia".

\section{Marco teórico-metodológico}

Este trabajo se apoya en el análisis iconográfico desarrollado por Erwin Panofsky y la definición de código icónico de Umberto Eco. Siguiendo al primero de estos autores, la iconografía se desarrolla como un apoyo a la historia del arte en base al aspecto externo de las imágenes, su descripción y clasificación (Castiñeiras, 1998). Según esta actividad, la imagen cuenta con tres niveles de significación:

- Nivel pre iconográfico: es el reconocimiento de la obra de arte en su sentido más elemental. Es el mundo de las formas puras que puede ser llamado de los motivos artísticos. Una enumeración de estos sería una descripción pre iconográfica de la obra de arte. Es llamado el significado primario o natural (Panofsky, 1980).

- Nivel iconográfico: en este nivel se trata de adivinar los contenidos temáticos de la obra de acuerdo recurriendo a la tradición cultural y a las fuentes 16 literarias. Radica en la relación de la obra de arte con un concepto propio de una tradición. Es el llamado significado secundario o convencional (Castiñeiras, 1998).

- Nivel iconológico: es el desentrañar los principios de fondo de la actitud básica de una nación, lapso temporal o creencia religiosa. Presupone una familiaridad con los conceptos tal como han sido transmitidos a través de las fuentes literarias o tradición oral (Panofsky, 1980).

Ahora, como es notable, para este método es fundamental la dependencia de fuentes escritas relacionadas a las imágenes por analizar. Dado el caso de Jama-Coaque como sociedad ágrafa, la aplicabilidad de este método se restringe a su primer nivel de categorización.

Sin embargo, el material cultural precolombino goza, si cabe el término, de mayor complejidad por su característica ágrafa. Esto quiere decir que los significados materiales que son más prácticos que el significado abstracto. Los significados materiales son no-discursivos, subconscientes, multidimensionales y múltiplemente codificados, características que los hacen más significativos contextualmente que lingüísticamente (Preucel y Hodder, 2006). Por lo tanto, entendemos que el material cultural precolombino puede ser recodificado, y por ende reinterpretado. Así, acogemos un análisis relacional y contextual como lo propone María Fernanda Ugalde (2009) en el que radica nuestra actividad de aproximación al significado de las aves en el material Jama-Coaque, que no pretende encontrar el significado auténtico en la sociedad precolombina en mención.

La descripción de las figuras se hace según el concepto de código icónico desarrollado por Umberto Eco (1986), conformado por figuras (condiciones para la percepción), signos (denotación de unidades de reconocimiento mediante artificios gráficos convencionalizados), y enunciados (imagen). Cuando se pueden dilucidar enunciados culturales se habla de códigos iconográficos. Por ejemplo, cuando no se habla de una figura de "serpiente emplumada" sino de "Quetzalcóatl". 
Una vez delimitado el conjunto de análisis, procuramos seguir las recomendaciones para una investigación de este tipo que señala Barthes (1993: 80), las cuales recomiendan que el corpus a analizar sea:

- $\quad$ suficientemente grande para ver sus semejanzas y diferencias,

- $\quad$ suficientemente homogéneo en su material, y

- comprimido en el tiempo.

\section{Material}

El análisis se realizó sobre un material fotográfico proporcionado de la Colección del Fondo Arqueológico del Museo Antropológico y de Arte Contemporáneo, del Ministerio de Cultura, ubicado en el Centro Cultural Libertador Simón Bolívar de la ciudad de Guayaquil ${ }^{4}$, y de la colección Ebnöther del Museum zu Allerheiligen de la ciudad de Schaffhausen ${ }^{5}$, Suiza. El no haber registrado directamente este material fotográfico puede constituir un sesgo y/o limitación de la investigación porque escapan a nuestra observación rasgos que habrían podido enriquecer el análisis, como por ejemplo la presencia leve de color en las piezas arqueológicas. Por lo tanto, nos hemos limitado a los elementos decorativos y corporales reconocibles en las fotografías, ya que las características principales del arte Jama-Coaque ${ }^{6}$ que se han mencionado hasta el momento son muy claras.

\section{Clasificación}

El ordenamiento del conjunto material analizado produjo 6 temas básicos: (I) personajes ornitomorfos, (II) personajes antropomorfos femeninos, (III) personajes antropomorfos masculinos, (IV) escenas con personajes ornitomorfos, (V) cabezas ornitomorfas, y (VI) fragmentos. Cada tema básico cuenta con subtemas de acuerdo a criterios importantes como la posición corporal del personaje (erguido, sedente) así como la posición de las alas en los personajes ornitomorfos, y la posición de las extremidades superiores e inferiores para los personajes antropomorfos.

Se ha procurado una descripción detallada en la definición de estos temas porque sostenemos que la variación en los patrones de representación de los personajes debe responder a significados diferentes. Es importante señalar que ninguna clasificación escapa del matiz subjetivo, y es lo más seguro que otros investigadores clasificarían nuestro material bajo otros criterios diferentes. Hemos revisado el conjunto material detalladamente lo que nos ha hecho probar diferentes clasificaciones previas a la presente.

\section{Convenciones iconográficas}

Previamente a tratar los temas formados, nos parece importante mencionar ciertas consideraciones previas. Hacemos hincapié en la diferencia temporal entre el momento actual y el momento precolombino que no permite una aproximación, física y temporalmente, a la cultura en estudio, pero la falta de estudios etnográficos para analogía es lo que más traba en tener una referencia para análisis comparativo. Una vez dicho esto podemos ver cómo se distribuyen las aves en la iconografía de Jama-Coaque.

4 Para motivos de acreditación de fotografías, haremos referencia de esta institución con las iniciales MAAC. Agradecemos la gestión de Carolina Jervis Rendón y Andrés Armijos, funcionarios de la Dirección Cultural Guayaquil, quienes ayudaron para la obtención del material fotográfico.

5 Para motivos de acreditación de fotografías, haremos referencia de esta institución con las iniciales MZAS. Agradecemos la gestión del curador de la colección, Werner Rutishauser, mediante el Dr. Alden Yépez en el Ecuador, para la obtención del material fotográfico.

6 Otra característica importante en Jama-Coaque es la diferenciación de los personajes antropomorfos dentro de la complicada parafernalia, descartando la posibilidad de una hibridación. 


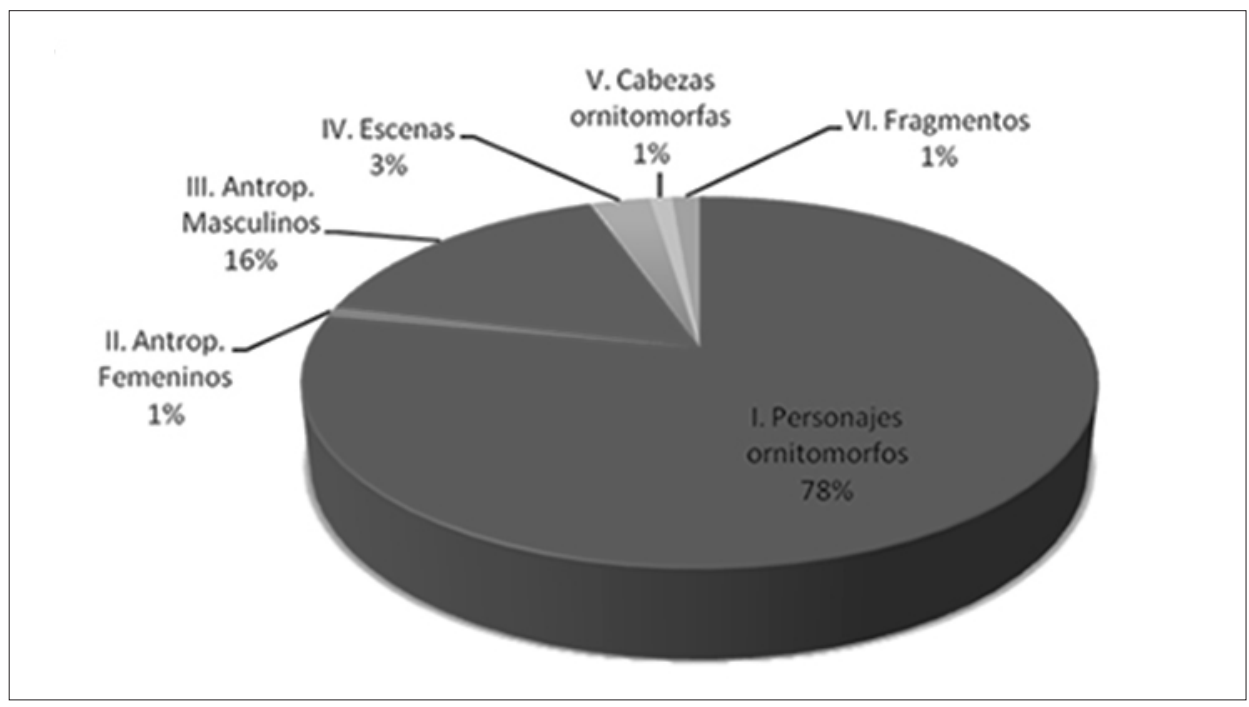

Gráfico 1. Estadística de temas formados

Como podemos ver, el tema de personajes ornitomorfos es el grueso del conjunto de análisis. Podemos decir que estas representaciones de diferentes especies de aves se encuentran sin asociación a otros tipos de personajes, como seres humanos u otras especies animales. En menor medida hay la asociación de varios personajes en escenas y como cabezas ornitomorfas.

Este grupo grande de personajes ornitomorfos se subdivide en varios grupos en base al diseño de ave representada en la pieza. Mayoritariamente se encontraron especies animales con las que estamos familiarizados en la actualidad; también se identificaron diseños con elementos de otras especies animales, y diseños cuya combinación de elementos muestran un personaje no natural.

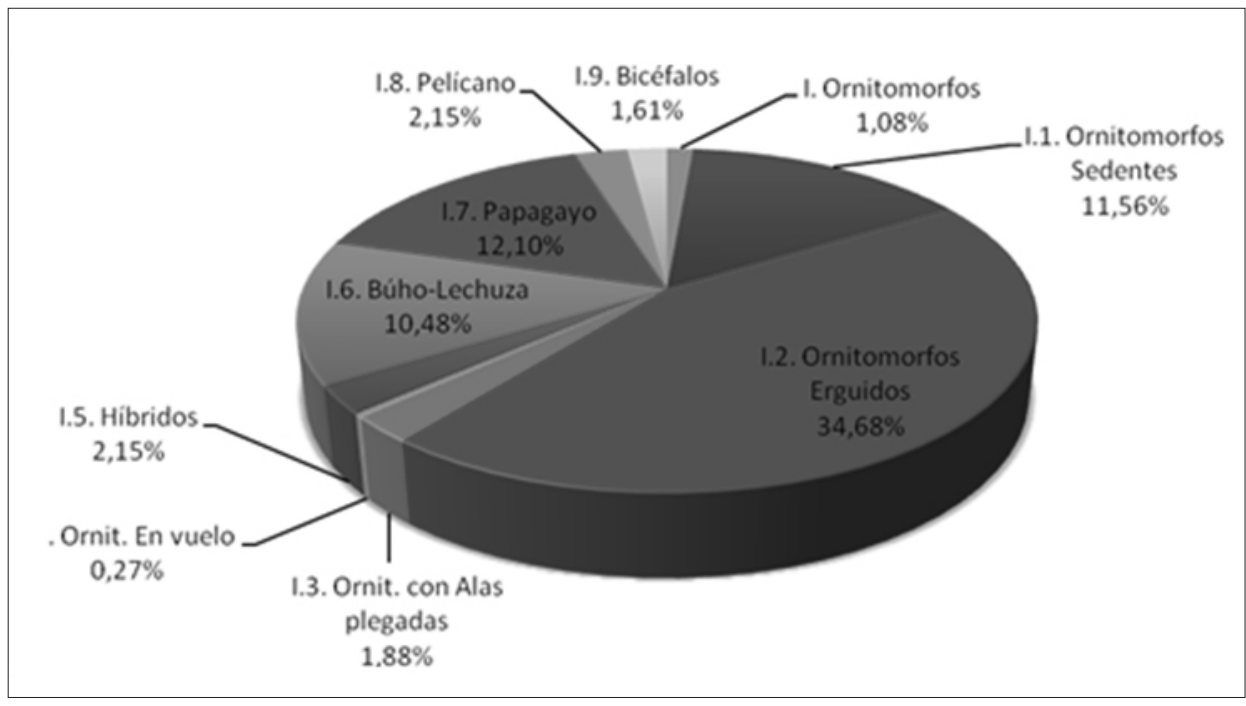

Gráfico 2. Subtemas de PERSONAJES ORNitomorfos 
Este tipo de imágenes se encuentra representado uno por pieza arqueológica, sea como silbatos o botellas. Generalmente estos diseños muestran a las aves en un estado natural, con poca o ninguna ornamentación, exceptuando los papagayos como veremos más adelante. Las aves, sin embargo, no se limitan a la representación como personajes. También se las encuentra como componente decorativo de vestimentas de seres humanos, como parte de recintos ceremoniales (Gutiérrez, 2012), principalmente aves sin especie definida?

La representación de aves en la cultura material de esta sociedad precolombina sigue ciertas tendencias generales. Con el propósito de ver alguna relación imagen-artefacto que permita dar alguna interpretación, observamos la relación proporcional entre estos dos componentes ${ }^{8}$. El resultado fue que un $56 \%$ del total de las aves se encuentran plasmadas en figurinas; es destacable que las representaciones naturalísticas se encuentran en pitos y/o figurinas silbato.

Se han identificado tres posiciones corporales de los personajes representados, tanto ornitomorfos como antropomorfos e híbridos: sedente, erguido y "en vuelo". La tendencia general es que los personajes se los represente en una posición erguida ya que cerca de tres cuartas partes del conjunto material $(74 \%)$ están representadas en esta posición. Esta tendencia muestra su mayor concentración en representaciones de personajes ornitomorfos erguidos.

Otro atributo que se toma en cuenta para el análisis es la posición de las alas, que es más específico y contenido en uno más general, la posición corporal. El conjunto muestra dos tipos de posición de las alas, "desplegadas" y "plegadas". También hay, aunque en escasa cantidad, otros casos en que se muestra solamente un ala desplegada. Los personajes ornitomorfos tienden a estar representados son alas plegadas $(59 \%)^{10}$.

Otra situación que se da es la exclusividad de atributos en determinados temas representados. El tamaño de la pieza es un atributo a considerar en este campo; las representaciones ornitomorfas están casi totalmente plasmadas en figurinas y/o silbatos, lo que hace que su tamaño sea pequeño en contraste con las representaciones antropomorfas.

\begin{abstract}
"No hay que olvidar que algunos contenidos de la imagen pueden ser expresados de una manera muy significativa a través de la morfología. Así, por ejemplo, el tamaño puede servir para expresar distintas ideas: de jerarquía, en el arte egipcio; de manifestación de lo supraterreno, en el arte medieval; o, simplemente, de edad, como en el grupo escultórico de Laocoonte." (Castiñeiras, 1998: 40).
\end{abstract}

Mediante la observación de elementos corporales se puede apreciar que no existe gran hibridación en el conjunto, confirmando el interés desmedido de Jama-Coaque por la figura humana. Al contrario, los elementos que se encuentran en otra especie a la que corresponderían son muy puntuales, y nos atrevemos a decir que aislados. Principalmente los colmillos y lenguas colgantes se concentran en los poco ejemplares de personajes híbridos con lo que podríamos decir que se tiende hacia una representación entre ave y felino. En cuanto a los demás elementos corporales en el resto del conjunto material, se puede ver la gran concentración en los temas correspondientes a especies de aves sin definición, exceptuando al papagayo.

Los ojos redondos son exclusivos de las representaciones ornitomorfas naturalísticas por su detalle bajo de manufactura. Su presencia disminuye considerablemente al pasar a las representaciones humanas en las cuales los ojos en forma de D destacan. Por lo tanto se pueden

7 A diferencia de Tolita, en donde los animales más frecuentes muestran características humanas, como el búho (Ugalde, 2009), las aves en Jama-Coaque no tienen estas características. Puede decirse que sucede al contrario porque hay una frecuencia importante de hombres disfrazados de aves, ricamente decorados especialmente las representaciones de alas de estos.

8 La descripción formal del material de análisis se ha seguido de acuerdo a la misma proporcionada por el museo o colección de procedencia. Los pocos casos no descritos, fueron hechos por nuestra parte.

9 Algunos de los ejemplares se tratan de figurinas que formaban parte de botellas comunicantes con diseño ornitomorfo.

10 Es curioso, a primera vista, que la categoría "inapreciables" le siga en proporción (32\%), pero este evento ocurre porque esta categoría contiene los casos de personajes antropomorfos, cabezas ornitomorfas y fragmentos, los cuales, obviamente, no tienen alas. Siguiendo la estadística se encuentran las alas desplegadas (8\%). 
ver exclusividad de representaciones para seres naturales, las aves, y para seres humanos, digamos culturales.

Profundizando en los elementos decorativos podemos ver una separación; los más simples concentrados en los personajes ornitomorfos ${ }^{11}$, mientras los tocados y collares principalmente, se concentran en los personajes antropomorfos.

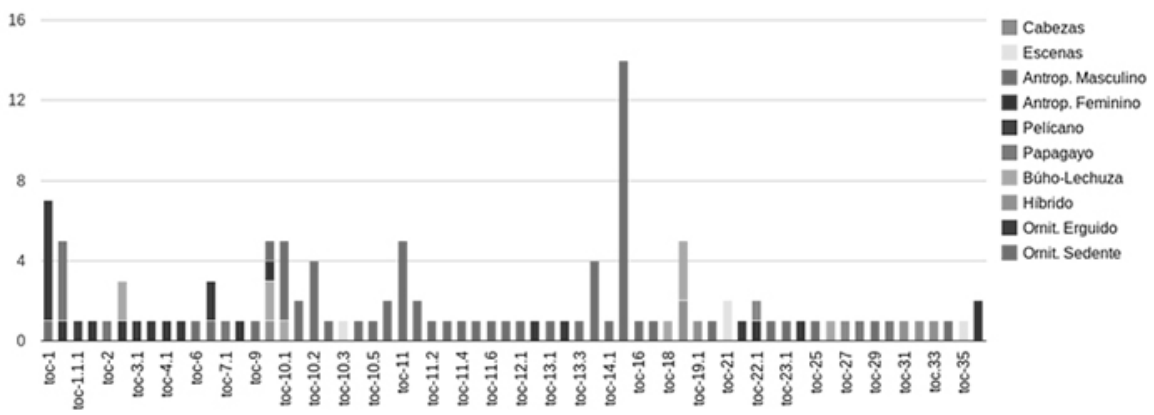

Gráfico 3. Distribución de tocados en las representaciones

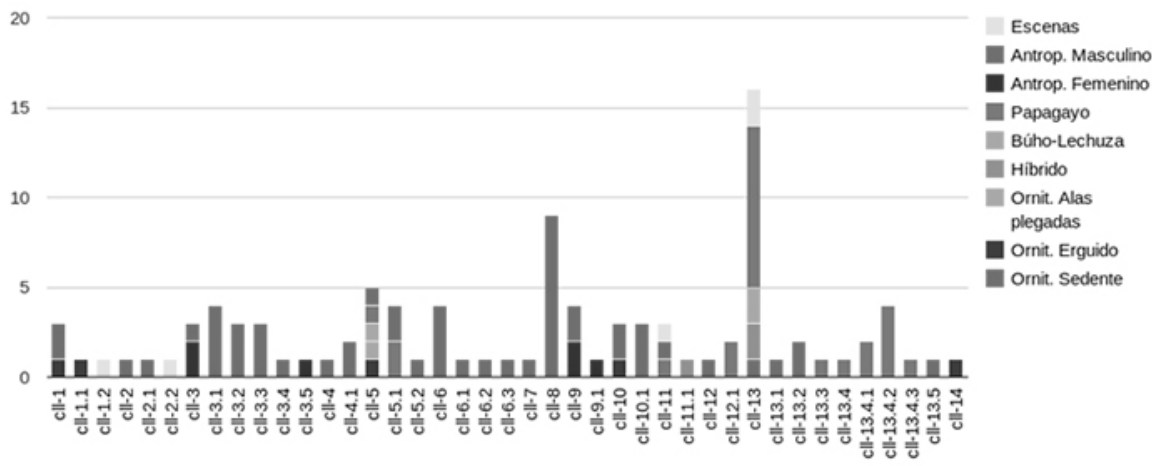

Gráfico 4. Distribución de collares en las representaciones

\section{Personajes ornitomorfos}

11 Representan un $77,95 \%$ del conjunto que se ha analizado. 
En este tema se encuentran las representaciones de aves sin especie definida. Aquí se incluyen cuatro subtemas que sólo cambian en su posición corporal y de alas. Estas aves no presentan atavíos con intensidad o una forma peculiar de representar al animal, lo que permite decir que no jugaría un rol ritual o importante en la vida social. Tanto sus elementos corporales como los escasos atavíos son simples; bandas o filas lisas. Sin embargo, la identificación de las partes corporales permite definir las diferentes especies representadas, acción que a su vez cumple con el análisis panofskyano "puesto que la identificación correcta de los motivos es el prerrequisito para un correcto análisis iconográfico en el sentido más estricto " (Panofsky, 1980: 18). Es importante decir que las especies presentes en el material no se encontraron en los rastros basurales del análisis llevado a cabo por Stahl y Zeidler, que en su mayoría son gallaretas ${ }^{12}$ (Zeidler et al., 1994).

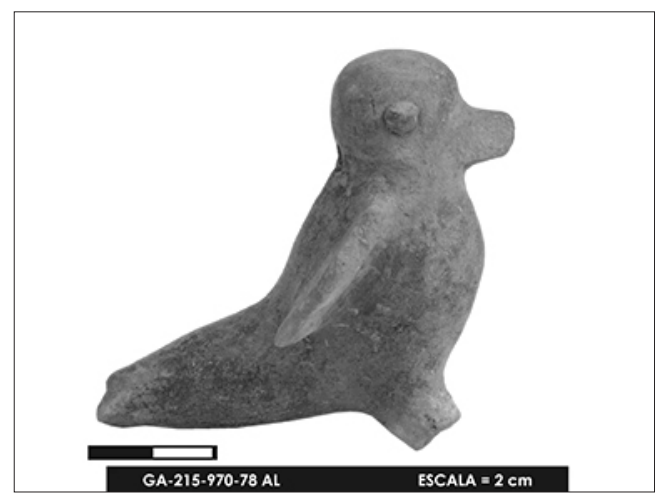

Figura 1. Figurina de cerámica de procedencia desconocida, MAAC, GA-215-970-78.

\section{Personajes híbridos}

En los pocos ejemplares de hibridación se ve claramente los colmillos y lengua colgante, por lo que la hibridación sería ave-felino. Estos personajes presentan cabeza y ojos redondos, con tocados tipo penacho y bezotes de doble fila enmarcando la boca. Hay una sola excepción de hibridación ave-humano en la que se ve el cuerpo antropomorfo y cabeza de papagayo, lo que nos da pie a interpretar al papagayo como ave de importancia para la sociedad Jama-Coaque. Es el mismo caso que se presenta en la cultura La Tolita (Ugalde, 2009) en donde su hibridación es esporádica. Según Gutiérrez (2002), es una representación de una especie de grifo en versión americana, tanto en Tolita como en Jama-Coaque.

La hibridación entre aves y felinos es una de las más frecuentes. Además, según Gutiérrez (Ibid.: 327 ), se fundamentan porque de esta manera el ser humano puede abarcar todos los elementos naturales, o algunos de ellos, que en este caso vendrían a ser el cielo o aire en el caso del ave, y el fuego y el agua celeste en el caso del felino.

El contraste se da en Moche donde en un sinnúmero de escenas se presenta el personaje con cuerpo humano y cabeza de búho sosteniendo un látigo, al pie del templo. Según Hocquenghem

12 Según Gutiérrez (2002: 298) existiría casi una correspondencia entre los animales que más docilidad y facilidad para la domesticación tienen y su presencia en vasijas, figurinas y silbatos, fauna que, por ende, no aparece en restos de alimentación en basurales. 
(1987: 105) es la representación del orden y la autoridad ligada a los mundos de abajo e interior, donde reina Viracocha Pachacamac.
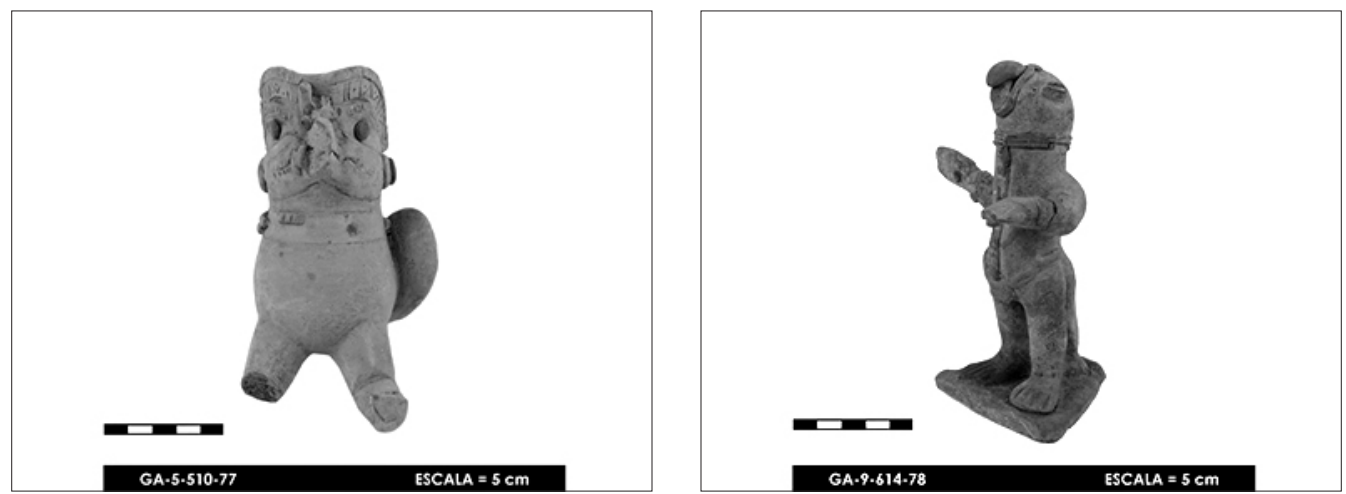

Figura 2. IzQUiERda: hibridaCión AVE-FELINO, FIGURINA dE CERÁMICA DE PROCEDENCIA DESCONOCIDA, MAAC, GA-5-510

DERECHA: HIBRIDACIÓN PAPAGAYO-HOMBRE, FIGURINA DE CERÁMICA DE PROCEDENCIA DESCONOCIDA, MAAC, GA-9-614-78.

\section{Búho-Lechuza}

Este tipo de representaciones presentan un pico en forma de gancho y un marco que encierra el rostro, cuya variación con plumas sobresalientes permiten identificar al búho específicamente. Los ojos se representan más grandes de lo normal, generalmente con una banda a su alrededor, lo que refuerza su visión desarrollada. En su decoración destacan dos tipos de tocados: de bandas que caen detrás de la cabeza, y circular que enmarca todo el rostro.

En el caso de mochica, las aves nocturnas presentan una preponderancia manifestada en su parafernalia y en sus rasgos de antropomorfización. Así tenemos el caso que mencionado anteriormente del personaje con cabeza de búho al pie del templo en la escena de la carrera, descrita por Hocquenghem (1987); Benson también menciona a personajes con rasgos de búhos antropomorfizados con indumentaria de guerreros además de aparecer en varios contextos como en vasijas y pinturas (Ugalde, 2009).

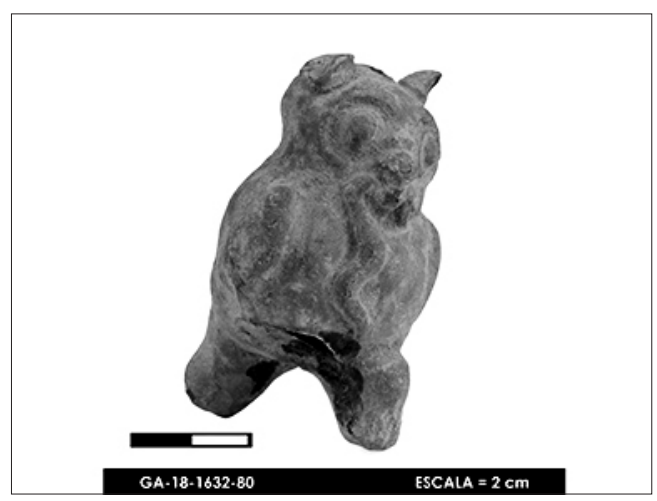

Figura 3. Figurina de cerámica de procedencia desconocida, MAAC, GA-18-1632-80. 


\section{Papagayos}

Estas representaciones se destacan por pico curvo, que se remite exclusivamente a estas aves, según nuestra observación. Escasos ejemplares muestran cejas dentadas o cejas decoradas, lo cual debe conectarse con su relación con los atavíos en el cuello. Se da una leve tendencia de tocados de banda decorada sobre la cabeza y un caso aislado de tocado tipo penacho.

Estos personajes presentan una particularidad; los collares de cuentas rectangulares y cuadradas con sus variaciones en la cantidad de filas. Este tipo de collares se encuentran con frecuencia en personajes antropomorfos, masculinos particularmente, con lo que se puede pensar en estas aves como símbolo de poder civil. La relación con el ser humano se refuerza con la presencia del aro que encierra al pico, con ciertas variaciones en el número de aros o en las partes del pico que encierra ${ }^{13}$.

Consideramos fuerte la relación con el ser humano porque, al igual que Ugalde (2009: 82), consideramos que estos atavíos también "antropomorfizan" al personaje, pese a que no se muestre una hibridación anatómica con el ser humano. Además, el papagayo junto con el jaguar, la serpiente y el mono, integra un complejo sistema del que se desconoce sus particularidades pero que, como vemos en el material, se vincula de forma manifiesta en el mundo ritual (Gutiérrez, 2002).

Hay que considerar un atributo al que ya nos referimos anteriormente: el tamaño. Como se ven en la figura 9 ambos personajes son casi del mismo tamaño. El hecho de que el ave tenga tal formato es un indicio que otorga estatus, que en este caso estaría relacionado al poder civilit ${ }^{14}$

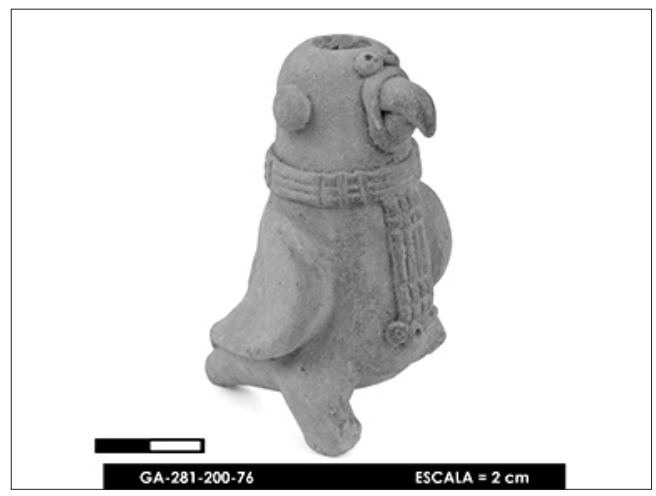

Figura 4. Figurina de cerámica de procedencia desconocida, MAAC, GA-281-200-76

\section{Pelícanos y bicéfalos}

Los personajes con rasgos de pelícano se caracterizan por la presencia de una cresta sobre la cabeza, esta última generalmente redonda o alargada, acompañada en la representación del personaje con picos rectos y largos, algunas veces pegados al pecho. Creemos que puede haber una relación entre esta especie de aves y el tipo de artefacto en el que están plasmados,

13 Un par de casos aislados presentaron diseños fitomorfos, sobre alas y espalda respectivamente. Otro caso aislado es la serpiente agarrada en el pico, rasgo característico de las aves nocturnas. Finalmente, también hubo escasos casos de pequeñas filas de bolitas en alas, cola o espalda.

14 Gutiérrez (2002) manifiesta que en todos los niveles de poder, la posesión de aves exóticas constituía un símbolo de prestigio, específicamente por los colores vivos de su plumaje el cual era la materia prima para la elaboración de vestimentas de la élite social, con el fin de relacionar a este grupo con la luz del día y el sol. Asimismo, esta especie de aves era objeto de sacrificios a la divinidad solar a lo largo del continente americano. 
posiblemente vinculados hacia la fertilidad ya que la cresta, según Gutiérrez (2002: 110 ) es el atributo biológico de los pelícanos machos en tiempos de reproducción, el cual es remarcado en nuestras representaciones.

Los personajes ornitomorfos bicéfalos, dejando de lado el rasgo innatural de la doble cabeza, no tienen una diferenciación de especies como sucede con las representaciones de aves que señalamos anteriormente. Su único rasgo es la presencia de un pico puntiagudo y corto. No presentan ningún elemento decorativo.
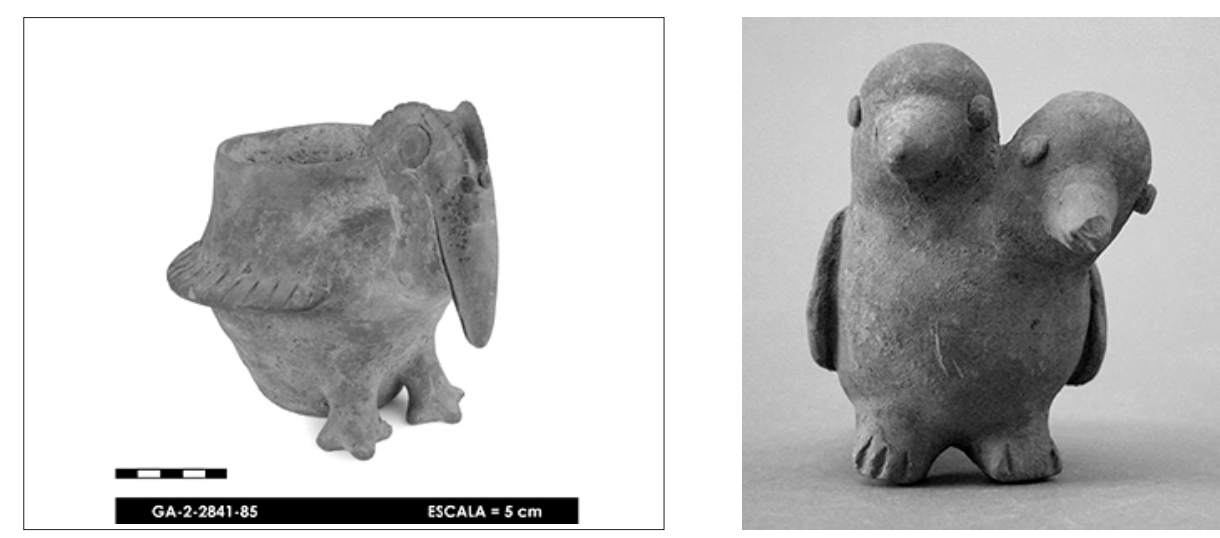

Figura 5. Izquierda: vaso de CERÁMiCA de PROCEDENCIA dESCONOCida, CON REPRESENTACión de PELÍCANO, MAAC, GA-2-2841-85.

Derecha: figurina bicéfala de procedencia desconocida, MZAS, Eb14128.

\section{Personajes Antropomorfos}

Lo primero que se destaca en los personajes antropomorfos es la abismal diferencia entre representaciones femeninas y masculinas. Las segundas son totalmente acaparadoras de la relación entre seres humanos y aves; son el 95\% de las figuras humanas. Esta desproporción creemos que implicaría una exclusividad de las aves como parte del contexto masculino.

Ahora, ambos sexos también tienen sus diferencias en cuanto a su representación. Las mujeres presentan una posición sedente, piernas estiradas hacia el frente, y manos sobre su regazo o elementos sobre este, siempre mostrando el busto descubierto y con la característica falda llana larga hasta las rodillas. Sus atavíos no tienen un mayor detalle en la elaboración.

El contraste es muy marcado con los personajes masculinos quienes mayormente están erguidos sosteniendo algún artefacto con sus manos. Según Thomas Cummins (Valdez y Veintimilla, 1992) la posición corporal en Jama-Coaque define los roles y posiciones sociales ${ }^{15}$. Así, distingue labores domésticas y de crianza de niños para las mujeres, y labores rituales, religiosas y civiles para los hombres. Los atavíos más elaborados están presentes en los hombres, tales como tocados y collares de varias filas con colgantes. Además: "la extrema importancia otorgada a la parafernalia ritual en el arte Jama-Coaque denota la existencia de una sociedad estratificada, en la cual la posesión de esos objetos marcaba el rango social y político” (Ibid.: $80)$.

15 Por la dualidad en la posición sedente entre ambos géneros, Gutiérrez (2012) propone que la cultura Jama-Coaque sea vista como una cultura filo-fálica, organizada entorno a la sexualidad masculina y a la fertilidad femenina. El autor, basándose en C. Plazas, propone un paso de la asociación de la fertilidad de las figuras femeninas en el formativo tardío a las figuras masculinas en el desarrollo regional donde los shamanes asumen este rol. 
El mismo caso sucede en la cultura Tolita (Ugalde, 2009) donde los elementos complicados, indicadores de rango como por ejemplo cetros, tocados ricamente elaborados, etc., son exclusivos para el género masculino que se encuentra, como en nuestro caso, en supremacía proporcional. De la misma manera sucede con los instrumentos musicales tales como rondadores y flautas de pan.

\section{Antropomorfos femeninos}

Estas representaciones tienen solamente tres ejemplares, situación que no permite dar una interpretación sobre los elementos identificados. Es importante el caso especial de la "mujer alada" que se difiere de lo señalado al mostrar ojos en forma de D y, principalmente, alas en la espalda. Los restantes ejemplares están en posición sedente mostrando los mismos tocados, narigueras y pulseras. Estos dos personajes pueden tratarse de las "joyeras" que hace referencia Gutiérrez (2012) por presentar adornos o elementos en su regazo. La falda llana es lo único que comparten los tres ejemplares, por lo que pensamos que la "mujer alada" puede pertenecer a una cultura vecina.
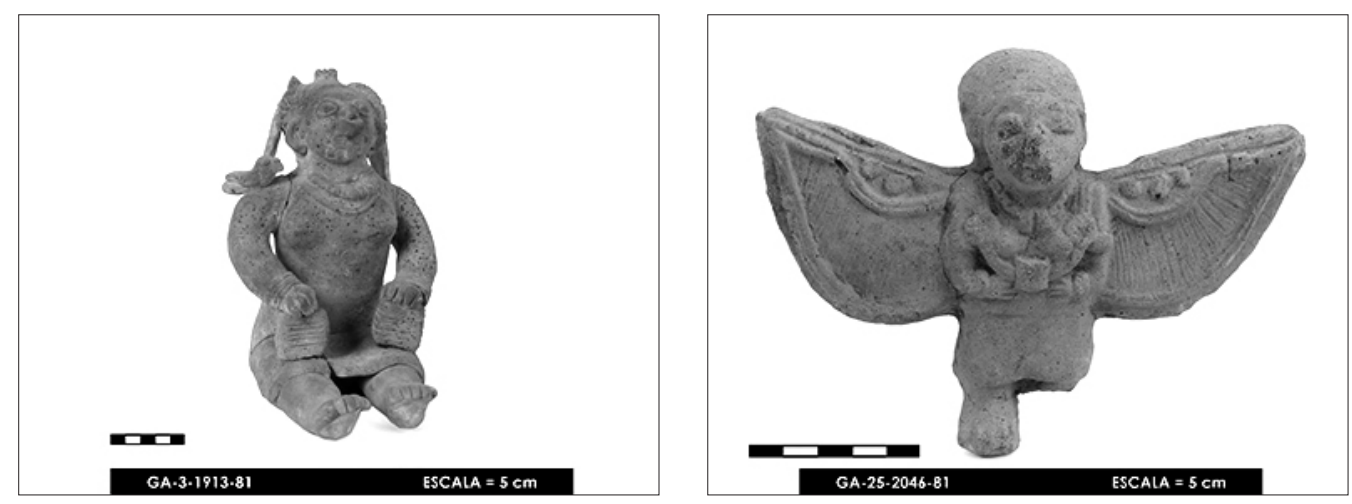

Figura 6. Izquierda: Figurina CERÁmica de Procedencia deSCONOCIDA, MAAC, GA-3-1913-81 Derecha: Figurina de CERÁmica de PROCEDENCIA deSCONOCIDA, MAAC, GA-25-2046-81.

\section{Antropomorfos masculinos}

Estas representaciones tienen una mayor variedad de posiciones en sus extremidades cuando están sentados ${ }^{16}$. Asimismo sucede con los elementos decorativos, especialmente tocados y collares, pese a que es un grupo pequeño del conjunto total. Además, los hombres son quienes exclusivamente usan instrumentos musicales, gracias a los cuales hemos podido reconocer dos tipos de personajes masculinos.

Uno de estos personajes es el hombre con tocado de aves al cual, debido a este atavío, no se le puede ver claramente la forma de su cabeza, que puede ser alargada o redonda. Además tienen torso descubierto, y ojos en forma de " $D$ " variando a ojos almendrados. El tocado de estos hombres puede variar en el número de aves que tiene; pueden ser una muy decorada o hasta siete aves cubriendo la cabeza. Casi siempre estos personajes van a estar portando una flauta de pan en sus manos, estableciéndose así la relación entre música y aves en tocado. Gutiérrez

16 En cuanto a extremidades inferiores varían en piernas dobladas y en posición de loto. Las extremidades superiores se muestran sobre las rodillas, con palmas hacia el centro, con palmas hacia el frente, sosteniendo la cabeza. 
(2012) define a este personaje como un shamán de luz, es decir que representa al sol y al color, cuyas aves en el tocado son símbolo de la estación seca cuando el sol permite el brote de nuevos frutos. Se contrapone al shamán con tocado de caracoles característico de la estación lluviosa, completando ambos un calendario agrícola en el que nuestro personaje representa la maduración y cosecha.
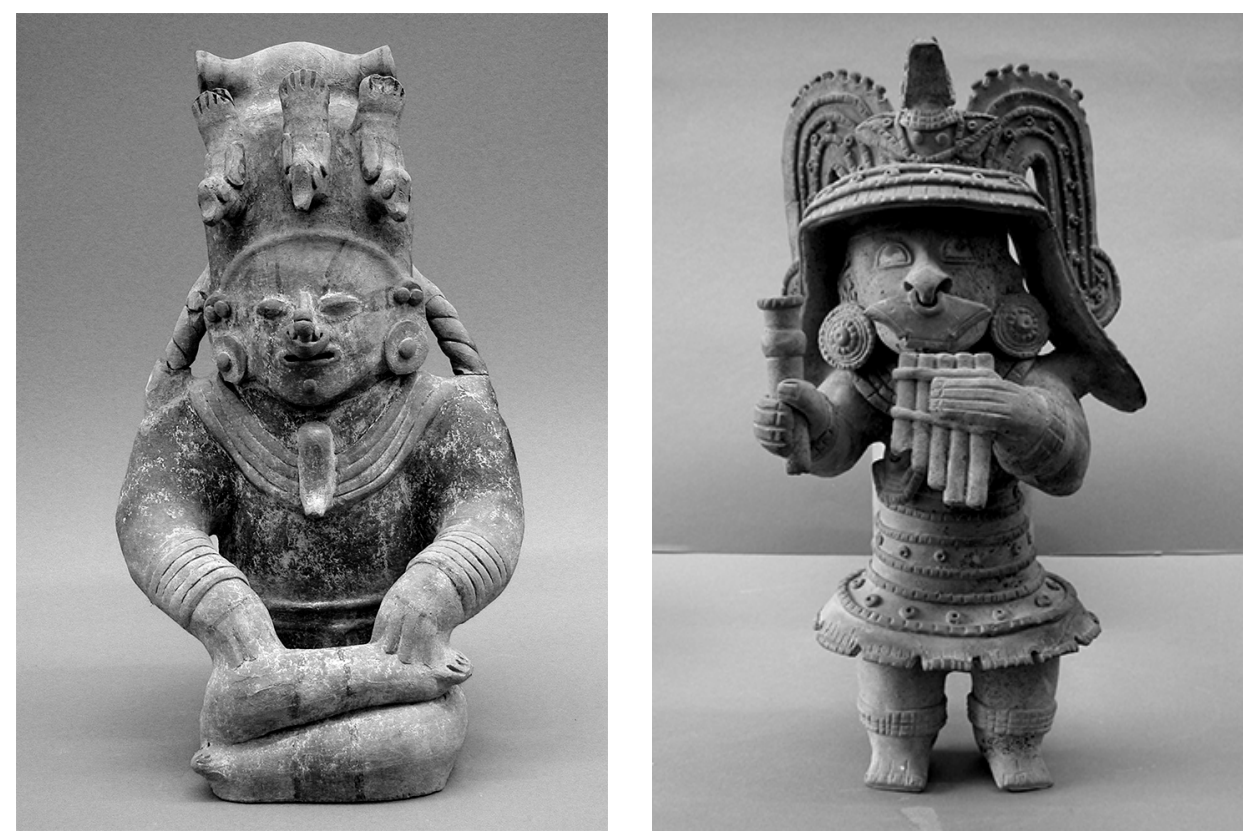

Figura 7. IzQuierda: Figurina Cerámica de Procedencia deSCONOCIDA, MZAS, Eb14405. Derecha: vaso Cerámico de procedencia desconocida, MZAS, Eb14084.

El segundo personaje identificado es un hombre con disfraz de ave. Decimos esto por la característica que mencionamos al inicio, que se ve al personaje debajo de tan complicada indumentaria. Tienen cabeza redonda bajo un tocado cilíndrico, torso cubierto por un traje plumario, y ojos en forma de " $\mathrm{D}$ " variando a almendrados. Estando exclusivamente en posición erguida, visten variedades de tocados trapezoidales y cilíndricos con colgantes o incrustaciones, aretes cuadrados, circulares o de medialuna. Además, siempre van a estar con sus brazos extendidos a los lados mostrando los diseños de las alas de sus trajes, los cuales pueden tener filas y bandas lisas, incrustaciones circulares o de arandelas, y pintura verde azulada. Lo importante de estos diseños de alas es que su organización nunca se repite, ni en sus fragmentos.

En un principio catalogamos a estos personajes como híbridos. Sin embargo, de acuerdo a los atributos corporales no se pudo establecer tal definición porque se mostraba claramente al personaje antropomorfo vistiendo una gran indumentaria sin rasgos de combinación anatómica con aves ${ }^{17}$.

17 María Fernanda Ugalde (2009) nos aclara esta distinción de personajes disfrazados y personajes híbridos para el caso Tolita. 


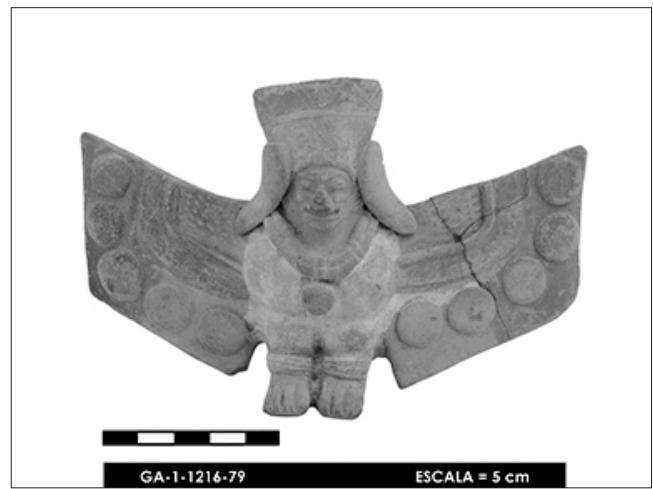

Figura 8. Figurina cerámica de procedencia desconocida, MAAC, GA-1-1216-79.

\section{Escenas}

En este tipo de representaciones se sigue con la tendencia marcada tanto para personajes ornitomorfos como para antropomorfos. Es decir, que estos últimos concentran las decoraciones mientras que las aves tienen un aro en sus picos. Para la figura de la derecha, es importante vincular al ave con el estatus del hombre a su costado. Para este tipo de escenas, Gutiérrez (2012) denota el tocado del hombre como un tocado vegetal, característico de las elites civiles, reforzado por el collar muy largo que cae sobre su regazo. El autor nos dice que la constante asociación de estos hombres con papagayos de gran tamaño se debe a que este animal representaría una divinidad o al espíritu del animal que simboliza un concepto.
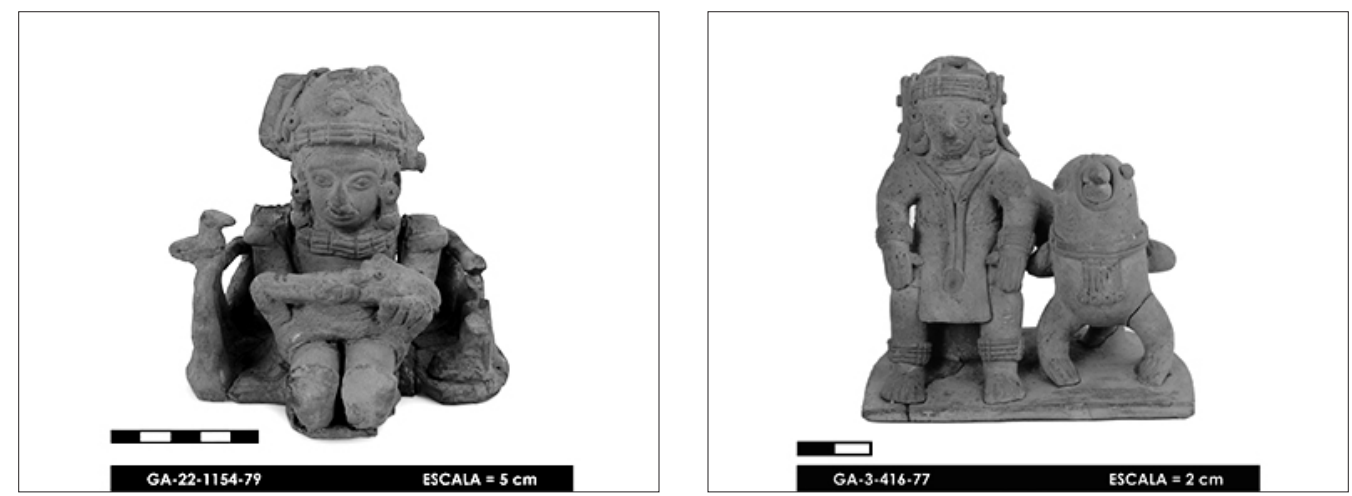

Figura 9. Izquierda: figurinas de procedencia desconocida, MAAC, GA-22-1154-79. Derecha: figurinas de Cerámica de procedencia desconocida, MAAC, GA-3-416-77.

\section{Cabezas}

Las cabezas ornitomorfas generalmente son redondas, con ojos redondos, pico puntiagudo y largo, con pocas crestas. Un caso especial presenta colmillos en el rostro. Los elementos decorativos se concentran en un solo ejemplar (ver figura 10). Los tocados son diferentes a los 
que se han visto en los personajes anteriores pero son muy escasos los ejemplares de cabezas para una mayor elaboración de tendencias decorativas.

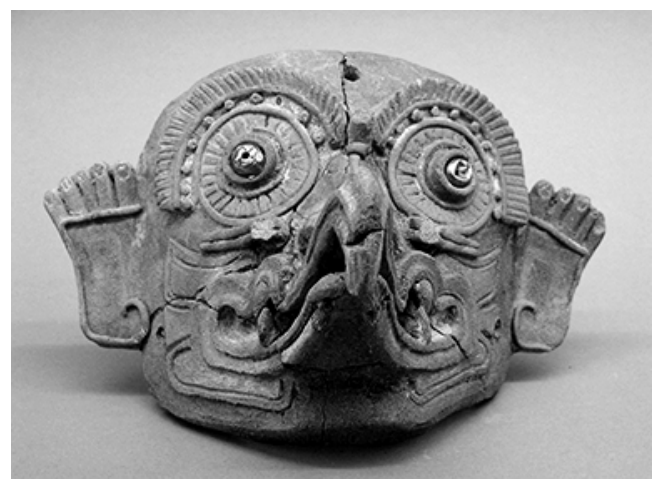

Figura 10. Cabeza cerámica de procedencia desconocida, MZAS, Eb14608.

\section{Fragmentos}

Los fragmentos son pedazos de alas sin patrón corporal que, por sus diseños, son parte de la vestimenta de los personajes antropomorfos masculinos con disfraz de ave. Ninguno de los diseños en los fragmentos se repite en los disfraces de los personajes en mención.

\section{Conclusiones}

Al final del proceso de análisis, podemos sacar en primera instancia tres patrones de representación. Un patrón ornitomorfo en el que la única diferencia corporal es la forma del pico, que permite diferenciar especies; plasmados en posición erguida con sus alas plegadas, ausente de adornos. Por lo tanto, las aves representadas en Jama-Coaque tienen un estilo naturalístico. El siguiente patrón es el híbrido ave-felino, en el que se reconocen aves de luz como aves nocturnas. Por sus pocos ejemplares no permite reforzar una interpretación sobre hibridación. El tercer y último patrón es el antropmorfo en el que las aves se restringen al contexto masculino, en decoración, indumentaria e instrumentos de los personajes. Proponemos una complementariedad entre hombres con tocado y hombres disfrazados de ave en los cuales los primeros serían músicos y los segundos danzantes, ejecutando ambos (no sólo el primero como sostiene Andrés Gutiérrez, 2012) rituales importantes para la comunidad, de acuerdo a un calendario agrícola.

El proceso de observación detallada de las piezas arqueológicas y las dificultades en ciertos detalles de la clasificación del conjunto nos han llevado a interpretar a las aves en la iconografía Jama-Coaque como hitos a través de los cuales el ser humano se define a sí mismo a la vez que las clasifica y aprehende. Es decir, los dos ámbitos de la vida humana, naturaleza y cultura, permiten la diferenciación social mediante una relación metonímica y metafórica. La primera de estas radica en la relevancia de los silbatos como contenedores de representaciones naturales de las aves, y en su posición erguida con alas plegadas. Esto es, que las aves en la sociedad Jama-Coaque eran valoradas y concebidas por el sonido que emiten, mas no por su carácter aéreo. A partir de esta aprehensión de las aves se genera la relación metafórica que se explica en la exclusividad de instrumentos musicales en los hombres con tocado de aves y su complementariedad con aquellos disfrazados de ave, para la representación de un concepto cultural, posiblemente ligado a un ciclo agrícola, y su desarrollo en ceremonias rituales dentro de la cultura Jama-Coaque. 
El conjunto material analizado constituye una pequeña parte del complejo universo JamaCoaque materializado en su arte plástico que aspiramos se constituya en una referencia para investigaciones que profundicen en el estudio de esta cultura precolombina. Pese a no abarcar una gran porción, si cabe el término, del universo Jama-Coaque, hemos podido ver a la cultura material como portadores de conocimiento, al igual que las palabras. De hecho, palabra y material son complementarios ya que el uno da conocimiento sobre el otro.

\section{Bibliografía}

Barthes, Roland, 1993, La aventura semiológica, editorial Paidós, Barcelona.

Castiñeiras González, Manuel Antonio, 1998, Introducción al método iconográfico, Editorial Ariel S.A., Barcelona.

Cummins, Thomas, 1996, Arte prehispánico del Ecuador. Huellas del Pasado: Los sellos Jama-Coaque, Museo del Banco Central del Ecuador, Guayaquil.

Eco, Umberto, 1986, La estructura ausente. Introducción a la semiótica, Editorial Lumen, Barcelona.

Estrada, Víctor Emilio, 1957, Prehistoria de Manabí, publicación del Museo Víctor Emilio Estrada, Guayaquil.

Gómez, Nelson, 1989, Elementos de la geografía del Ecuador: El hombre y el medio, EDIGUIAS Cía. Ltda., Quito.

Gutiérrez Usillos, Andrés, 2012, El Eje del Universo. Chamanes, sacerdotes y religiosidad en la cultura Jama Coaque del Ecuador Prehispánico, Ministerio de Cultura (España), Museo de América, Ministerio de Cultura del Ecuador, Madrid.

2002, Dioses, símbolos y alimentación en los Andes. Interrelación hombre-fauna en el Ecuador prehispánico, Abya-Yala, Quito.

Hocquenghem, Anne Marie, 1987, Iconografia Mochica, Fondo Editorial de la Pontificia Universidad Católica del Perú, Lima.

Hodder, Ian, 1994, Interpretación en arqueología. Corrientes actuales, Editorial Crítica, Barcelona.

Panofsky, Erwin, 1980, Estudios sobre iconología, Alianza Editorial, Madrid.

Porras G., Pedro I., y Luis Piana B., 1976, Ecuador prehistórico, Instituto Geográfico Militar IGM, Quito.

Preucel, Robert W., 2006, Archaeological Semiotics, Blackwell Publishing, Oxford, UK.

Preucel, Robert W., e Ian Hodder (Eds.), 2006, Contemporary Archaeology in Theory. A reader, Blackwell Publishing, Oxford, UK.

Saville, Marshall, 1907, The antiquities of Manabi, Ecuador: Final Report. Contributions to South American Archaeology. Volume II, Columbia University, New York, USA.

Tilley, Christopher, 1999, Metaphor and Material Culture, Blackwell Publishers, Oxford, UK.

Tobar Abril, Oswaldo E., 1988, Prospección arqueológica de la cuenca del Río Cangrejo en San Isidro Manabí Norte: el uso de criterios hidrográficos para el muestreo probabilístico, Tesis de grado previa a la obtención del título de Licenciado en Arqueología, ESPOL, Centro de Estudios Arqueológicos y Antropológicos, Guayaquil.

Ugalde, María Fernanda, 2009, Iconografía de la cultura Tolita. Lecturas del discurso ideológico en las representaciones figurativas del Desarrollo Regional, Reichert Verlag (ed.), Wiesbaden, Alemania.

Urton, Gary (Ed.), 1985, Animal Myths and Metaphors in South America, University of Utah Press, USA.

Valdez, Francisco, y Diego Veintimilla, 1992, Signos amerindios: 5000 años de arte precolombino en el Ecuador, Dinediciones, Quito.

Yépez, Alden, 2010, Fenderkopfputz und Körperschmuck bei den Jama-Coaque, en Mit fremden Federn. Antike Vogeldarstellungen und ihre Symbolik, Werner Rutishauser (ed.), Editorial Hirmer, Schaffhausen, Suiza.

Zeidler, James, et al, 1994, Arqueología Regional del Norte de Manabi, Volumen 1. Medio Ambiente, Cronología Cultural y Subsistencia Prehistórica en el valle del Río Jama, University of Pittsburgh, Department of Anthropology, Ediciones Libri Mundi Enrique Grosse-Luemern, Quito, Pittsburgh. 